\title{
Assessing the impact of energy saving measures on the future energy demand and related GHG (greenhouse gas) emission reduction of Croatia
}

Article in Energy · July 2014

Impact Factor: 4.84 · DOI: 10.1016/j.energy.2014.06.045

CITATIONS

9

4 authors:

Tomislav Puksec

University of Zagreb

38 PUBLICATIONS 82 CITATIONS

SEE PROFILE

Tomislav Novosel

University of Zagreb

15 PUBLICATIONS 38 CITATIONS

SEE PROFILE

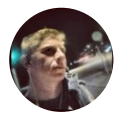

Brian Vad Mathiesen

Aalborg University

81 PUBLICATIONS 3,026 CITATIONS

SEE PROFILE

Neven Duic

University of Zagreb

409 PUBLICATIONS 1,637 CITATIONS

SEE PROFILE 


\title{
Assessing the impact of energy saving measures on the future energy demand and related GHG (greenhouse gas) emission reduction of Croatia
}

\author{
Tomislav Pukšec ${ }^{\text {a, }{ }^{*}, \text { Brian Vad Mathiesen }}{ }^{\text {b }}$, Tomislav Novosel ${ }^{\text {a }}$, Neven Duić a \\ ${ }^{a}$ Department of Energy, Power Engineering and Environment, University of Zagreb, Faculty of Mechanical Engineering and Naval Architecture, \\ Zagreb, Croatia \\ ${ }^{\mathrm{b}}$ Department of Development and Planning, Aalborg University, Denmark
}

\section{A R T I C L E I N F O}

\section{Article history:}

Received 29 November 2013

Received in revised form

10 June 2014

Accepted 12 June 2014

Available online 22 July 2014

\section{Keywords:}

Energy planning

Future energy demand

GHG (greenhouse gas) emissions

Energy policy

\begin{abstract}
A B S T R A C T
In the light of European energy-climate package and its measures for increasing security of supply, decreasing the impact on environment and stimulating sustainability, Croatia as a new EU (European Union) member state needs to reconsider and develop new energy policy towards energy efficiency and renewable energy sources. Croatian long-term energy demand and its effect on the future national GHG (greenhouse gas) emissions are analysed in this paper. For that purpose the NeD model was constructed (National energy demand model). The model is comprised out of six modules, each representing one sector: industry, transport, households, services, agriculture and construction. The model is based on bottom up approach. The analysis has shown that energy policy measures, identified through this paper, can potentially achieve energy savings up to $157 \mathrm{PJ}$ in the year 2050 , which presents a $40 \%$ decrease to referent (frozen efficiency) scenario. Results obtained in this paper were also compared to the Croatian National Energy Strategy for the years 2020 and 2030. It was shown that if already implemented policies were properly taken into account the actual final energy demand for the year 2030 would be $43 \%$ lower than projected by the Croatian National Energy Strategy.
\end{abstract}

() 2014 Elsevier Ltd. All rights reserved.

\section{Introduction}

Croatia has experienced a steady growth of final energy demand until 1990 with a peak of $275.67 \mathrm{PJ}$ in 1987 [1]. Industry consumed $38 \%$ of the final energy at that time, transport $20 \%$ and other sectors combined for the remaining 42\% [1]. Following the collapse of the Socialist Federal Republic of Yugoslavia and the ensuing war, Croatia's industry was devastated and the overall energy consumption, especially in the industry sector, experienced a substantial decline. The transport and other sectors began to recover and the energy demand started to increase again. The total final energy

Abbreviations: NeD model, national energy demand model; HED model, households energy demand model; IED model, industry energy demand model; EDT model, energy demand in transport model; MAED, model for analysis of energy demand; LEAP, long range energy alternatives planning; GHG, greenhouse gas; EU, European Union; GDP, gross domestic product.

* Corresponding author.

E-mail addresses: tomislav.puksec@fsb.hr (T. Pukšec), bvm@plan.aau.dk (B.V. Mathiesen), tomislav.novosel@fsb.hr (T. Novosel), neven.duic@fsb.hr (N. Duić). consumption reached the pre-war levels by 2010 [1]. The industrial sector, however, never recovered. The energy consumption of Croatia's industry remained at the post-war level until 2008 when it experienced another drop caused by the European wide recession. The final energy consumption of the industry, transport and other sectors in Croatia from 1985 until 2011 is shown in Fig. 1. Households, services, agriculture and construction are included under other sectors.

Classical energy demand planning is usually focused on establishing relationship between economic variables such as GDP (gross domestic product) and energy consumption $[2,3,4]$. This is usually done based on analysing different historical data and processing them in a relatively simple way, like time series analysis, or applying more complex analyses using neural networks, genetic algorithms or similar methods $[5,6]$. It is argued that this approach has become inefficient in the case of EU (European Union) countries which strive towards decoupling their economic growth and energy consumption. Numerous initiatives towards lowering energy consumption in the EU by implementing different Directives, financial schemes and mechanisms, that should result in lowering 


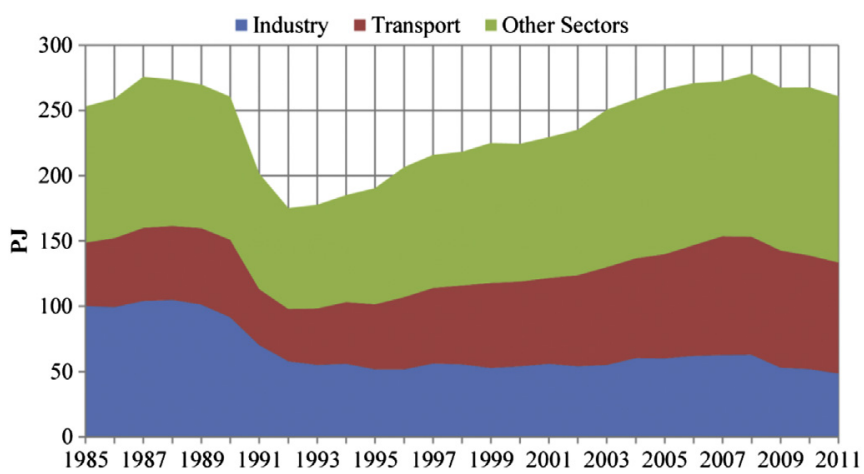

Fig. 1. Final energy consumption by sectors in Croatia [1].

energy demand in the future, substantiate this argument $[7,8]$. If the primary energy consumption and the GDP growth are compared, it is visible that in Croatia's case these two factors are still linked. The increase in GDP is followed by the increase in energy demand until the late 2000s when the country experienced a crisis lowering the GDP, and as a result the energy consumption has decreased as well [14]. GDP and the primary energy consumption for Croatia for the period from 1992 until 2010 are presented in Fig. 2.

Decoupling economic growth and energy consumption is possible. Implementing various energy policy measures could lead to significant decrease of energy consumption and GHG (greenhouse gas) emission in Croatia until 2050. The same data as shown in Fig. 2 for Croatia is shown in Fig. 3 for Denmark. Evidently Denmark has successfully decoupled their increase in GDP and energy consumption. This means that Denmark has increased its overall energy efficiency while Croatia still has to achieve the same (goal).

Croatian final energy intensity is presented for the period from 1995 until 2010 in Fig. 4. Generally declining trend could be noticed, which would mean a gradual increase of energy efficiency.

Generally, energy demand planning can be done using one of the two main approaches, top down or bottom up approach $[9,10]$. In order to construct all six economic sectors bottom up approach was used. $\mathrm{NeD}$ (national energy demand) model presents a highly detailed model whose main purpose is to show how future energy demand is influenced by various mechanisms. Engineering bottom up energy demand models, which focus on end users, usually can have a better overview and evaluation of potential future energy savings. End use demand is affected by the cost of energy, but more importantly it is affected by other mechanisms such as legislation,

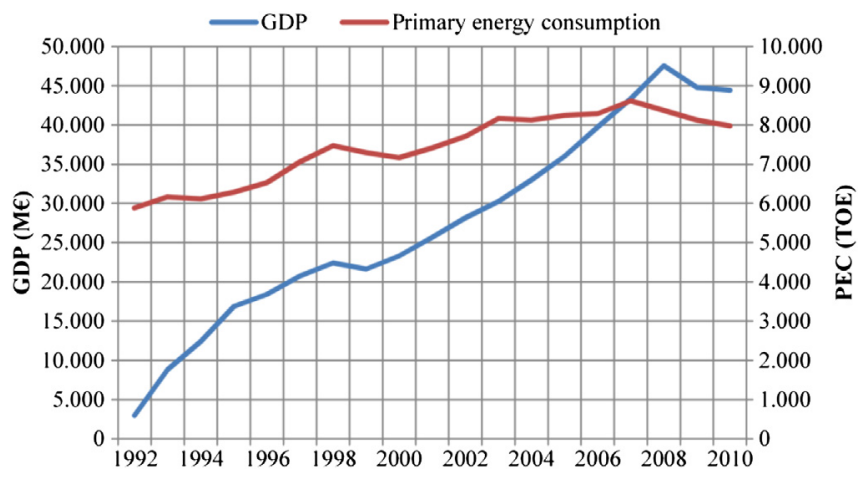

Fig. 2. GDP growth and primary energy consumption in Croatia [14].

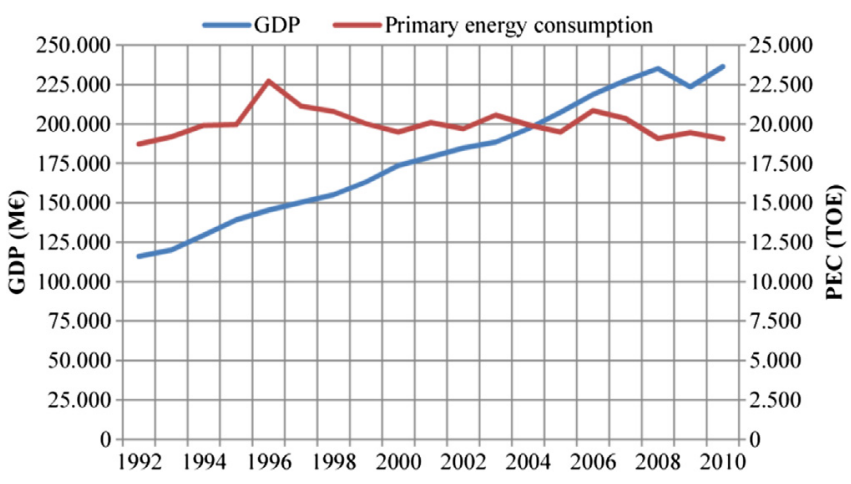

Fig. 3. GDP growth and primary energy consumption in Denmark [14].

financial schemes, technological development, climatic conditions, etc. This feature is crucial in order for the new energy policies and strategies to be created and tested [11]. Downside of this approach is the extensive input data that has to be gathered and systemized $[12,13]$. This is especially problematic for countries with data deficiency, both statistical and energy balance wise. In those cases building a bottom up model can be very difficult. Bottom up approach, focused on the end users, can be described with the following general steps, as defined by the UN (1991) and IAEA (2006) [14]. First step would include the identification of relevant end use categories and their categorization. Afterwards a detail analysis of influencing factors is necessary to set the mathematical relationships. Next, reference year analysis is a must because it allows testing the methodology and mathematical relationships. Finally, scenario approach needs to be applied to quantify all the modelled measures and mechanisms.

\section{Methodology}

In order to analyse Croatia's final energy demand and construct its long-term energy demand projection, NeD model was constructed. The model was comprised out of six modes, each representing one economic sector: households, industry, transport, services, agriculture and construction (Fig. 5). The development of the model was done through stages, with a detailed long-term energy demand model, of one economic sector, presented in each stage. Since every previously developed model was constructed in MS Excel tool, their synthesis was relatively easy. The final stage in the construction of the NeD model was the creation of a GHG emission mode that would unify and cover all six sectors.

Since one of the main intentions of NeD model was to decouple economic growth from the energy consumption and focus on different energy policies as main driving parameters influencing future energy demand, very detailed engineering model based on the end-use categories was the only valid approach. NeD model presents a valuable tool which can be used for the integral energy planning process. Projecting future energy demand is a starting point for any future advanced system analyses where energy demand data presents a key input parameter $[16,17]$. NeD model can support supply side oriented energy planning models and tools in a more accurate energy system analyses $[18,19]$.

For the purposes of this paper similar long-term energy demand models were analysed and tested. Main intention was to analyse their advantages and disadvantages. The two most interesting ones, regarding energy demand planning, were LEAP (long range energy alternatives planning) and MAED-D (model for analysis of energy demand). LEAP presented a good accounting energy demand/supply model with the advantage of being easy to use and the input data not too extensive $[20,21]$. At the same time, it did not present 


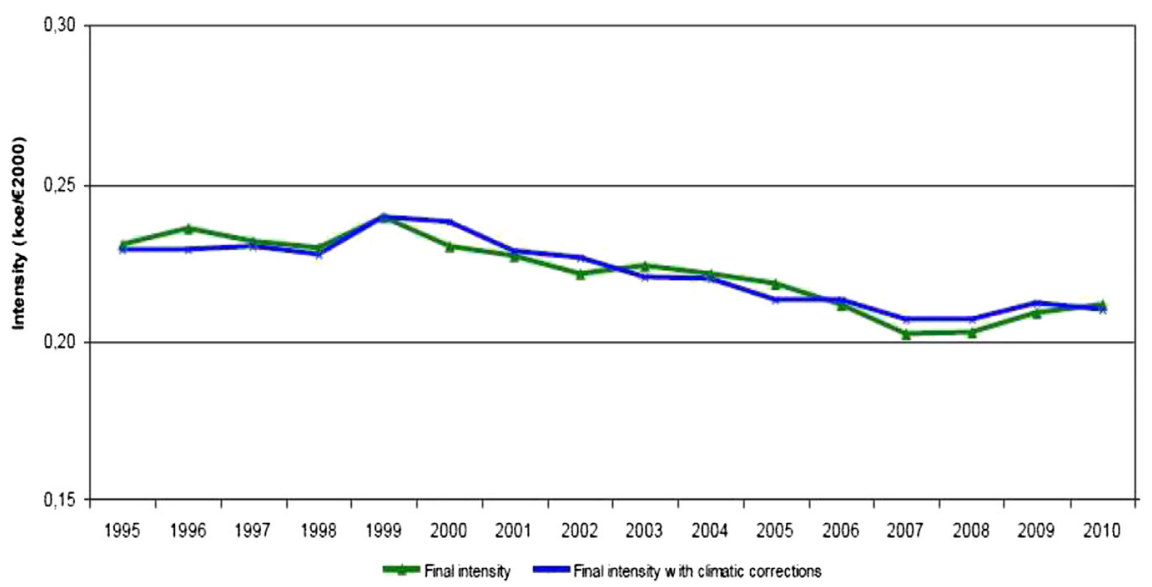

Fig. 4. Croatian final energy intensity until 2010 (Vuk B et al., Energy efficiency policies and measures in Croatia, ODYSSEE MURE project, 2012).

the level of details if compared to NeD model which, for instance, has the ability to model heat/cooling demand of households and services sector on an hourly level for any year until 2050. This was especially important because the main intention of NeD model was to use its results as input data for supply side models.

The main disadvantage of accounting models, including NeD model, was their inability to perform any type of optimization that could result in the least costly solution. Second bottom up energy demand model tested on Croatia as a case study was MAED-D. Here the model was less user friendly and required detailed and specific input data which could be difficult to obtain [22, 23]. Additional disadvantage of MAED-D was its inability to modify model structure which could be very interesting and useful in some cases. The advantage of MAED model was the fact that it was a well structured and organized model, which allowed an easy start of the modelling process. MAED model can be considered as a starting point of the NeD modelling methodology. However NeD model presents a significant upgrade and improvement in comparison to the MAED model, especially in the terms of useful energy demand calculations of the households and services sectors. Another advantage of the MAED model was its MAED-el part, which allowed partial downgrade of yearly electricity consumption to an hourly level.

This paper is structured as follow; in the methodology part overview of all six economic sectors will be presented. Long-term energy demand models for the households sector [24], industry $[25]$ and transport [26] have already been published by the authors, so here they will be referenced and very briefly explained. The remaining three sectors will be covered in a more detailed way since they have been recently constructed especially to be incorporated into the NeD model. Final section of the methodology part will focus on the GHG emission calculation methodology. Most interesting findings will be presented and discussed in the results paragraph and finally main conclusions will be given.

One of the biggest advantages of the NeD model was its ability to model various energy policy scenarios through endogenous parameters. This allowed more accurate calculations when energy

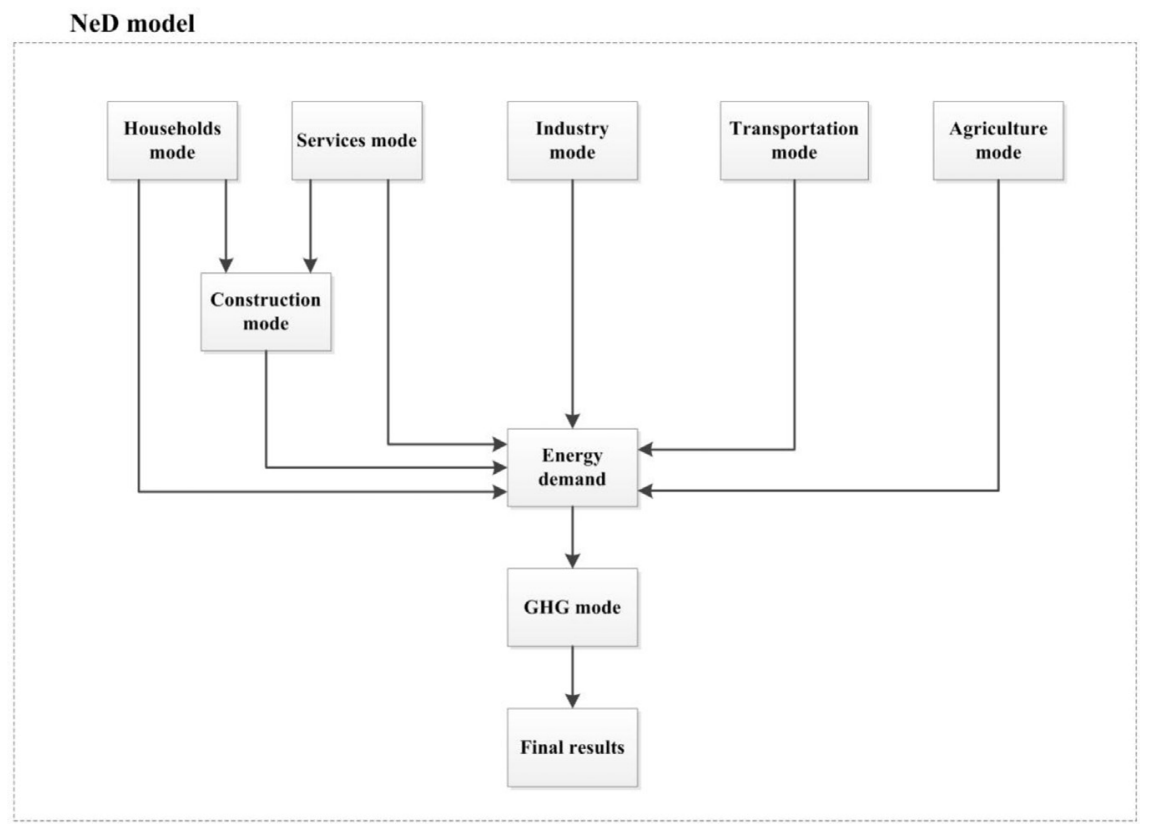

Fig. 5. NeD model overview. 


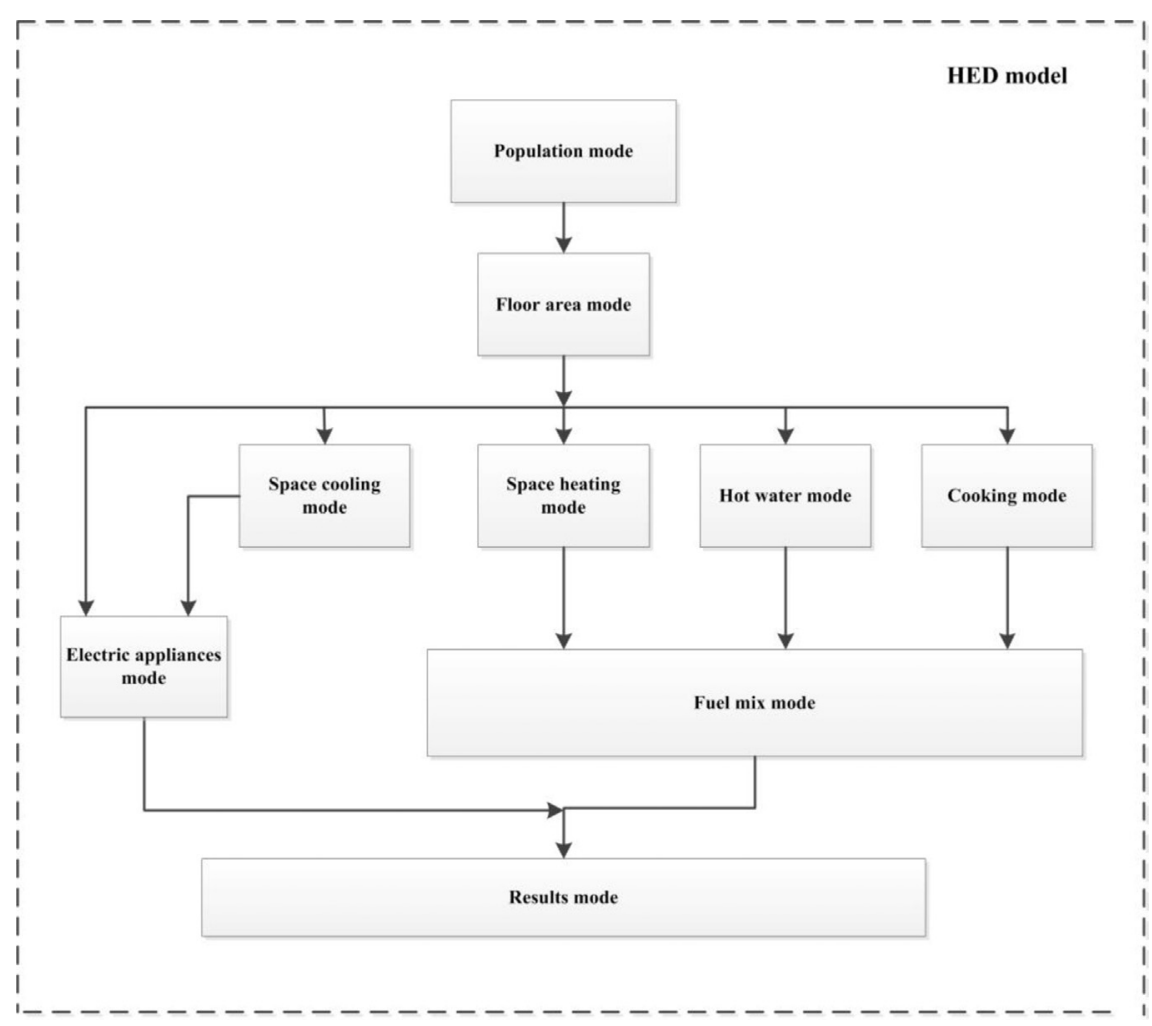

Fig. 6. Overview of the households energy demand calculation.

demand projections were made. NeD model was constructed from six individual energy demand projection modes all based on bottom up approach. They all work by calibrating its methodology on one reference year which was chosen by the user. In the following paragraphs main equations and logics of each sector will be presented as well as the final part of the NeD model, which was the GHG emission mode.

\subsection{Households sector}

NeD households sector was constructed by importing and adopting HED (households energy demand model) methodology, previously developed for the Croatian households sector [24]. The main logics in calculating future energy demand are presented in Fig. 6. To calculate space heating and cooling demands, as well as energy needed for cooking, hot water and electric appliances, population and available floor surfaces needed to be calculated first. When calculating available floor surfaces, all floor surfaces that would have been renovated, newly built and demolished in every year until 2050 were calculated. Available floor surfaces were calculated on the NUTS $3^{1}$ level. After the available floor surfaces, outer envelope surfaces were calculated and the basic thermodynamic equations for useful space heating/cooling demand were set. Thermodynamic calculations were based on quantifying transmission and ventilation losses from one side and internal and solar gains on the other. All demands, except electric appliances, were first calculated at the useful energy level. Afterwards, in the fuel mix mode useful energy was transferred to final energy level, combining different technologies and market shares.

\footnotetext{
${ }^{1}$ Nomenclature of Territorial Units for Statistics.
}

\subsection{Industry sector}

NeD industry sector was constructed by importing and adopting IED (industry energy demand model) methodology previously developed for the Croatian industry sector [25]. There were four major parameters, when it came to energy demand projections, covered through this methodology. Special focus was given to export/import component which determined the ratio of domestic production capacities resulting changes in energy demand. First, consumption per capita has been integrated in the IED model with the purpose to incorporate the influence of population on product consumption. Consumption per capita in reference year has been taken as a starting point for future periods modelling. Calculation was applied to each of the nine industry subsectors to obtain detailed results for the main structure. Production for domestic market and import were directly linked, which meant that the production situation for domestic market could be significantly influenced by making changes in import trends. As a result certain flexibility was added to the model where exact shares could be set. Production for export was directly regulated through determining amounts of export quantities for the reference year, which were obtained from the Croatian Bureau of Statistics, and export change in the future periods. All possible outcomes of the energy consumption, whether the trend was rising or falling, were fully covered controlling the export in this manner. The exact amounts of production quantities determined the flexibility of export control. Phasing out or introducing certain types of industry also played an important role because these changes could significantly influence the energy demand. The best example of phasing out is the textile industry which, in the last decade, has almost completely disappeared in Croatia. Efficiency component was considered to examine the influence of technology advancements on future energy demand. General structure and logics for calculating industry 


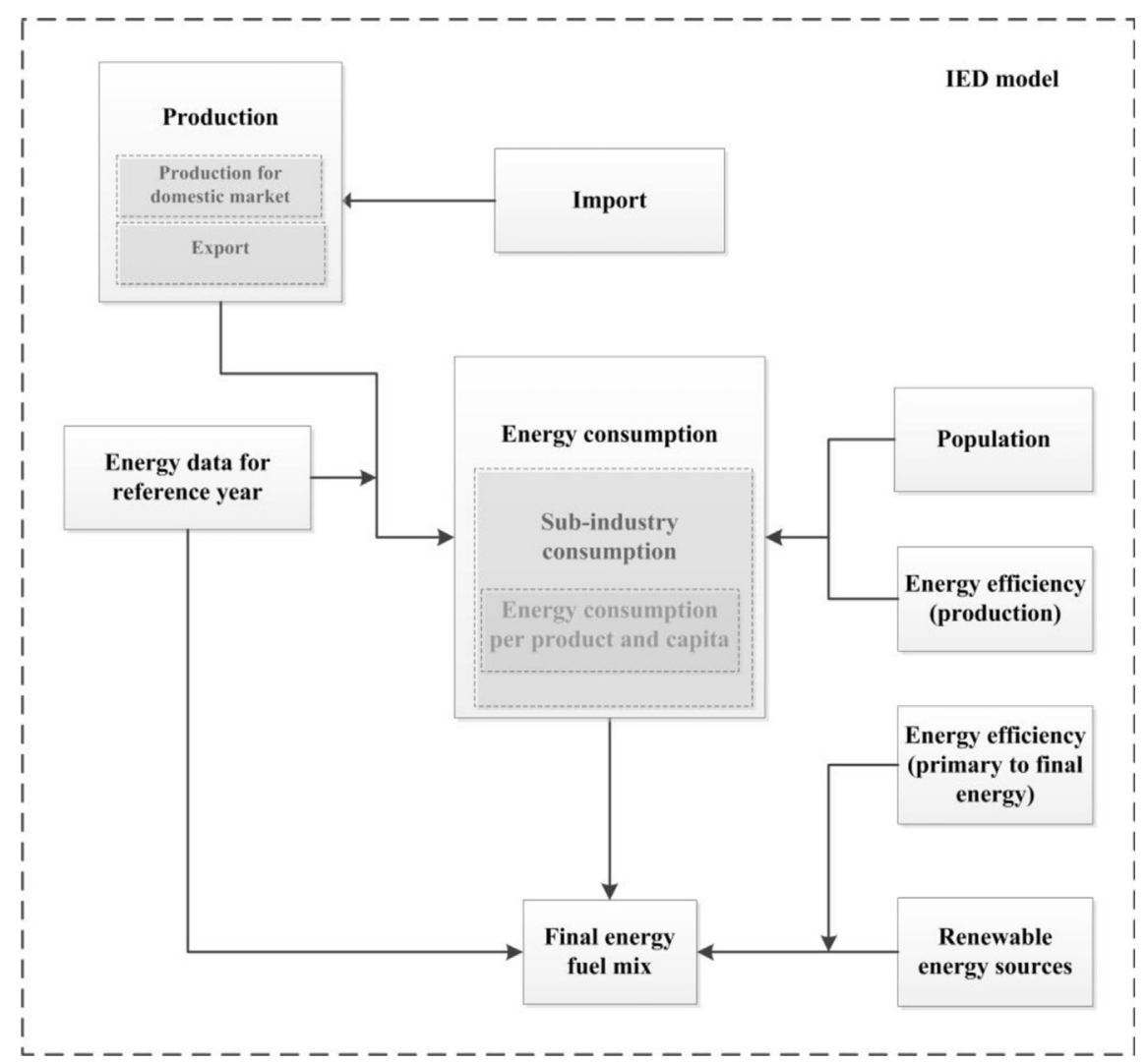

Fig. 7. Overview of the industry sector energy demand calculation.

energy demand is presented in Fig. 7. The last major parameter was the fuel mix which provided the opportunity to further improve the future energy demand according to the assumptions related to phasing out certain fuels and adding new, more environmentally friendly, alternatives as well as renewable energy sources. All four parameters were tested in the reference year to verify the suggested methodology which would be used later on for future energy demand predictions.

\subsection{Transport sector}

NeD transport sector was constructed by importing and adopting EDT (energy demand in transport model) methodology developed previously for the Croatian transport sector [26]. The methodology was based on the principle of covering and analysing every subsector (road, rail, sea and river, air and public transport) separately and then summing their contributions in the final energy demand balance. Every subsector was specific in the energy demand calculation procedure, but one unified note could be identified. Calculations were based on modelling the dynamics of the end-users until 2050 (vehicles, trains, buses, aircrafts, ships, trams, etc.), their efficiency, usage, availability, etc. This dynamics was based on calculating yearly values for all end-use categories entering and exiting the system.

For personal vehicles, the number of personal vehicles entering the system was calculated based on two levels. First, the number of alternative personal vehicles entering the system (electric and hybrid vehicles) was calculated. Based on their dynamics, the number of other personal vehicles that run on conventional fuels (gasoline, diesel and liquefied petroleum gas) entering the system was calculated. Thus, for every alternative vehicle entering the system, a certain percentage of conventional vehicles was reduced. The numbers of electric and hybrid vehicles entering the system were calculated based on market penetration $S$ curves. First, all statistical data needed to be imported into the model to start the necessary calculations. Afterwards, based on the reference year, all missing and unavailable parameters could be calculated and tested, which was the main condition before starting to predict future energy demand. Different scenarios, that could show and quantify how different energy policies influence future energy demand, could be set.

A cross-subsector connection only occurred when calculating the modal split among road, air and rail transportation. The energy value of each tone kilometre and passenger kilometre until 2050 was calculated. After that the modal split dynamics was set, and the tone kilometres and passenger kilometres were transferred from one subsector to another. General overview of the methodology and calculation procedure is shown in Fig. 8.

\subsection{Services sector}

Final energy demand of the services sector was calculated by summarizing all subsectors and their final energy demands. Service subsectors analysed through NeD model were: education, tourism and catering trade sector, health, commerce and government. For tourism and catering trade sector, methodology presented in [27] was used. For the rest of the service subsectors HED methodology [24] was mainly applied, adjusting certain parameters to capture all the specifics. For instance, when calculating final energy demand of commerce and government sector, energy for cooking was not included. Geographic distribution during calculation procedures 


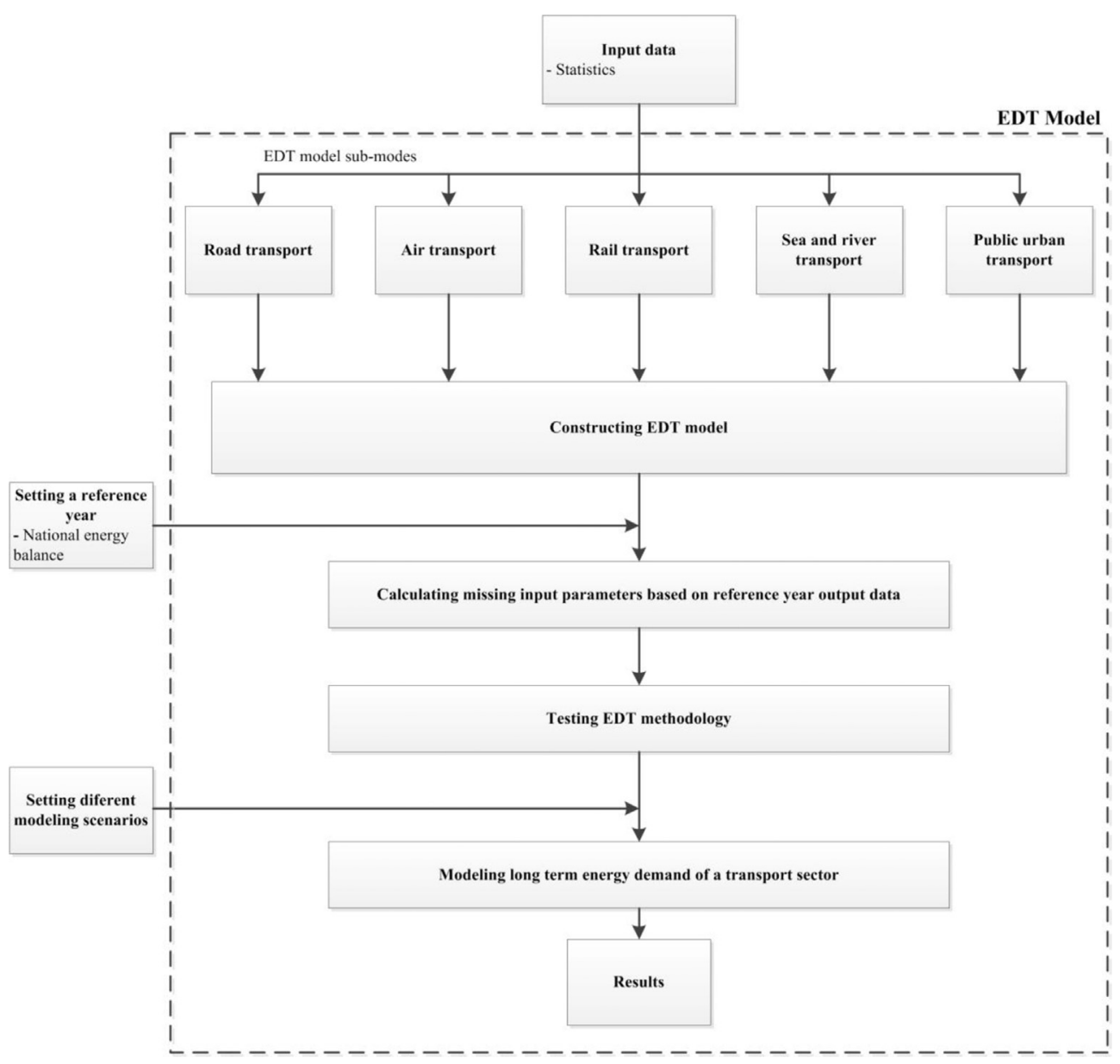

Fig. 8. Overview of the energy demand planning methodology of a transport sector.

was not set to the county level, like in the HED model applied to households, but at the regional level to South, East and Northwest Croatia. Available floor area was modelled based on the specific available surface per capita for different kind of service subsectors:

$A_{\mathrm{i} \text { spec }}^{\mathrm{z}}=\frac{B_{\mathrm{i}}^{\mathrm{z}}}{P^{\mathrm{z}}}\left[\frac{\mathrm{m}^{2}}{\mathrm{capita}}\right]$

After the available floor surfaces, outer envelope surfaces were calculated and the basic thermodynamic equations for useful space heating/cooling demand, using HED model equations, were set. Thermodynamic calculations were based on quantifying transmission and ventilation losses from one side and internal and solar gains on the other.

Energy demand of the health subsector was calculated for eight different categories:

- Hospitals

- Institutes of public health

- Clinics

- Health centres

- Pharmacies

- Care organizations

- Other health institutions

- Health companies

These categories were chosen based on the statistics formed by the National Bureau of Statistics. This rule was applied to most of the modes because it allows for the NeD model to be validated by some future research and results. The difference in applying the HED model for services sector was the way the outer buildings envelope surface was calculated. While for the households sector the outer buildings envelope surface was calculated by a complex thermodynamic equations [24], for the services sector simpler approach had to be applied, due to a lack of quality data on available floor surfaces and building characteristics. When calculating available buildings outer envelope surface for the health, education, government and commerce subsectors average ratios between available floor area and outer envelope surfaces were calculated based on the gathered statistical information. Based on that information thermodynamic equations for useful heat and cooling demand, described in Refs. [24], were calculated.

Energy demand of the education subsector is calculated for four different categories:

- Kindergartens

- Primary schools

- Secondary schools

- Universities

Energy demands of the commerce and government subsectors are calculated for five different establishments depending on the number of employees. Chosen categories are:

- Establishments with 0-9 employees

- Establishments with 10-19 employees 
- Establishments with 20-49 employees

- Establishments with 50-249 employees

- Establishments with $250+$ employees

The main focus was given to the tourism and catering trade sector since its increase in activity, energy wise, was assumed. Based on that assumption individual model has been developed [26] and its methodology and calculation procedures were implemented into the NeD model. Methodology for calculating energy demand of the tourism and catering trade sector was based on determining energy transferred through the outer envelope surface and "other consumption", which contained various electric equipment, water heating, etc.

\subsection{Agriculture sector}

The agriculture sector represented about $4 \%$ of the Croatian final energy demand with $10.27 \mathrm{PJ}$ in 2010 [1]. Even though it is not a very substantial amount because the agricultural activity is an important aspect of the country's economy, more detailed energy demand analysis had to be made. To calculate the energy consumption, agriculture sector was first divided into crop husbandry and animal husbandry subsectors. Both subsectors were then further divided into family farms and industrial farms, and finally onto specific productions (corn, wheat, barley, etc. for the crop husbandry; and cows, pigs, sheep and poultry for the animal husbandry).

The energy consumption of the crop husbandry subsector was calculated according to the equations (2) and (3):

$\mathrm{EI}_{\mathrm{a}}=\frac{E_{\mathrm{a}}}{P_{\mathrm{a}}}$

$\mathrm{EC}_{\mathrm{a}}=\mathrm{EI}_{\mathrm{a}} \cdot \mathrm{CP}_{\mathrm{a}}$

The energy consumption of the animal husbandry subsector was calculated according to the equation (4):

$\mathrm{EC}_{\mathrm{ah}}=\mathrm{EI}_{\mathrm{ah}} \cdot \mathrm{NOE}$

Historical data for the production of specific crops and the raising of certain animals were taken into account, as well as the ratio between small family and larger industrial farms. Calculated results were then compared to the data obtained from Ref. [1] and the difference between the two turned out to be negligible.

\subsection{Construction sector}

Although not usual in energy planning, construction sector was included into the NeD model. Primary reason for this was to follow the national energy balance and national statistics and to allow similar future studies to compare NeD results. Construction sector was usually included into the transport or industry sector when calculated with similar models. Energy demand model for calculating the construction sector was based on the national statistic which covered six main energy consumption categories: residential; non-residential; transport infrastructure; pipelines, communication and electricity lines; complex construction on industrial sites; and other civil engineering works. For every of the six mentioned categories fuel mixes were calculated: LPG, diesel, gasoline, electricity, heavy oil and renewable energy sources.

Equation (5) represents the main calculation procedure used for each fuel type in each energy consumption category.

$F_{\mathrm{ij}}^{\mathrm{z}}=L_{\mathrm{ij} \mathrm{spec}}^{\mathrm{z}} \cdot C_{\mathrm{j}}^{\mathrm{z}} \quad[\mathrm{PJ}]$
With $i$ representing the fuel type and $j$ representing the energy consumption category (residential, non-residential etc.). Based on the energy consumption category, units for the $L_{\mathrm{ij} \text { spec }}^{z}$ and $C_{\mathrm{j}}^{z}$ were determined. If the calculation was made for residential and nonresidential the units used were $\left[\mathrm{PJ} / \mathrm{m}^{2}\right]$ and $\left[\mathrm{m}^{2}\right]$. In case of other four energy consumption categories units used were [PJ/construction site] and [number of construction sites].

Cross connection of NeD model was visible through energy demand calculation of residential and non-residential energy consumption categories. All the newly build available floor surface that have been calculated in the households and services sector were imported into construction sector model as an input data. Based on this data energy needed for constructing all those new floor areas was calculated.

\subsection{GHG emission mode}

Only $\mathrm{CO}_{2}$ emissions from all six economic sectors were calculated in the current version of the NeD model. After the energy demand and the fuel mix was calculated for every sector, this information was imported into the GHG mode. So every energy policy that would influence future energy demand would at the end influence future $\mathrm{CO}_{2}$ emissions as well. GHG mode was structured based on the IPCC ${ }^{2}$ parameters. IPCC data for every fuel, in $\mathrm{tCO}_{2} / \mathrm{TJ}$ was used. These data were default but different sets of data could be imported into the model if necessary. When it came to electricity, all electricity from all six economic sectors was summed up and then the national conversion factor for electricity $\left(\mathrm{kgCO}_{2} / \mathrm{kWh}\right)$ was applied. The conversion factor, which depends on the country was imported into the model as an input data. For the purposes of this paper Croatian conversion factor was used. This conversion factor was dependant on the electricity generation fuel mix and could vary from year to year. This is the case especially in countries relying strongly on hydro power. In the process of calculating GHG emissions of district heating, national conversion factor was also applied $\left(\mathrm{kgCO}_{2} / \mathrm{kWh}\right)$.

Basic principle of GHG calculation can be presented by the following equation:

$G_{\mathrm{i}}^{\mathrm{Z}}=S_{\mathrm{i}}^{\mathrm{Z}} \cdot K_{\mathrm{i}}^{\mathrm{Z}}\left[\mathrm{tCO}_{2}\right]$

where $i$ presents the fuel type for which the emitted $\mathrm{CO}_{2}$ was calculated while the conversion factors were basically set depending on the fuel observed.

\section{Results and discussion}

Through this paragraph main results calculated by NeD model will be presented. Since most interesting results and scenario options have already been presented for households, industry and transport sectors, here, the focus will be on the remaining sectors and on the whole country's final energy demand and GHG emissions. To fill in the NeD model various data sources were used: Croatian energy balance ${ }^{3}$, Croatian National Bureau for Statistics, EUROSTAT [15], different databases such as Odyssee ${ }^{3}$ or IPCC. For every sector input data sources vary, but the ones mentioned are standard.

Four different scenarios of the Croatian services sector can be seen in Fig. 9. First scenario was the one with the frozen efficiency, while the following three represented three different yearly renovation rates of available floor surfaces. If the two most extreme

\footnotetext{
${ }^{2}$ Energija u Hrvatskoj - http://www.mingo.hr/default.aspx?id=3258.

3 http://www.indicators.odyssee-mure.eu/energy-efficiency-database.html.
} 


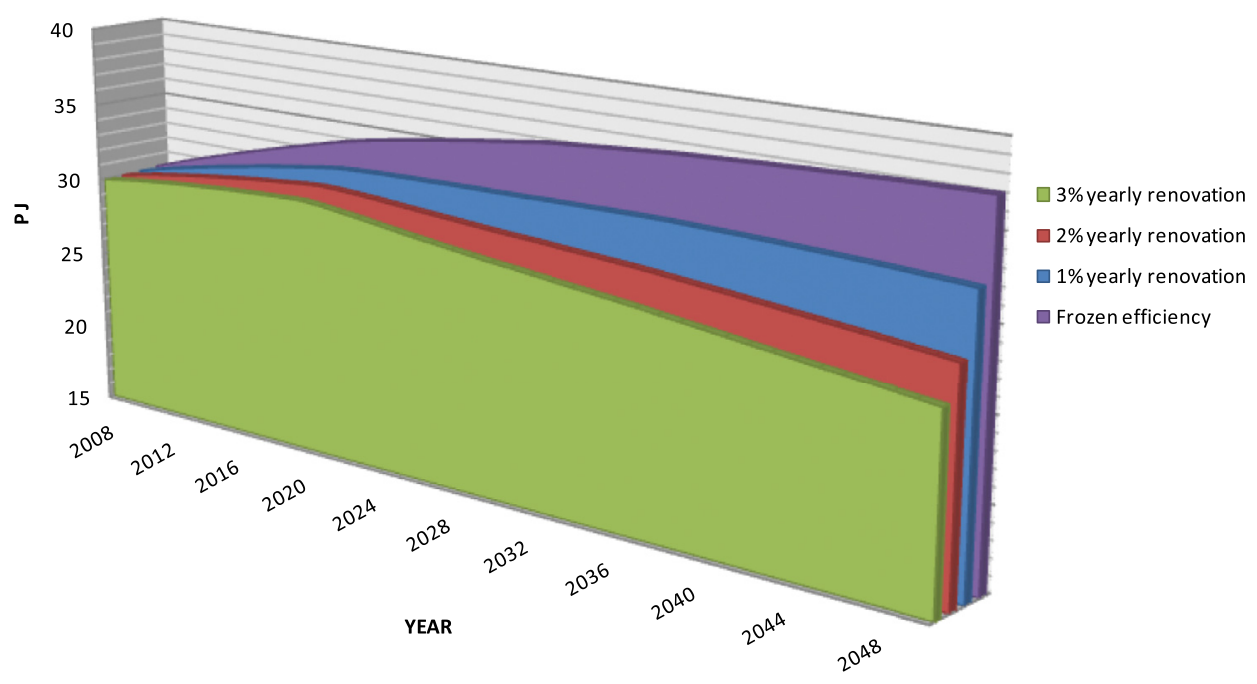

Fig. 9. Long term energy demand scenarios of Croatian services sector.

scenarios, frozen efficiency and 3\% renovation rate are compared, energy demand in the year 2050 could be $28 \%$ lower. The renovation rate was directly connected to the EU Directive 2012/27/EU on energy efficiency which clearly states the yearly renovation rates for public buildings. Although fuel mix could have been considered as supply side energy planning, NeD model had the possibility of transferring the useful energy demand into final energy demand by introducing different technologies and their efficiencies. This is a very important feature of NeD model because modelling long term useful energy demand allows influencing mechanisms that relate to building physics (insulation, building materials, building codes, yearly renovation rates, etc.) to be quantified. The second step (transition from useful to final energy demand) allows various technologies, fuel switches, technology efficiencies, etc. to be modelled. In Fig. 9 all four scenarios are represented with the following fuel mix ratio for space heating purposes in the year 2050: $60 \%$ heat pumps, $20 \%$ district heating and $20 \%$ biomass.

If analysing the $3 \%$ yearly renovation scenario of the services sector further, one of the most interesting results was the fuel mix
(Fig. 10). As could be expected, electricity had the steepest long term increase with almost $70 \%$ in the final energy demand in the year 2050. This was in line with the all electrification trend. All services subsectors tended to increase the level of electric appliance and devices. And with the introduction of heat pumps as space heating/cooling solution, increase in ratio of electricity in the services sector was expected. Liquid fuels were expected to have a total phase out until the year 2050, while gas fuels would have had insignificant share in the same year. As an alternative to gas and liquid fuels, electricity, biomass and district heating would have been heavily introduced. This was in line with the EU directives on energy efficiency and RES which were especially favourable towards district heating/cooling. Lower temperature district heating was expected, with higher share of renewable energy sources and waste heat.

One of the energy efficiency scenarios of the construction sector can be seen in Fig. 11. Unfortunately due to the specifics of the work required and technologies available which were closely connected to heavy machinery, this sector was expected to stay

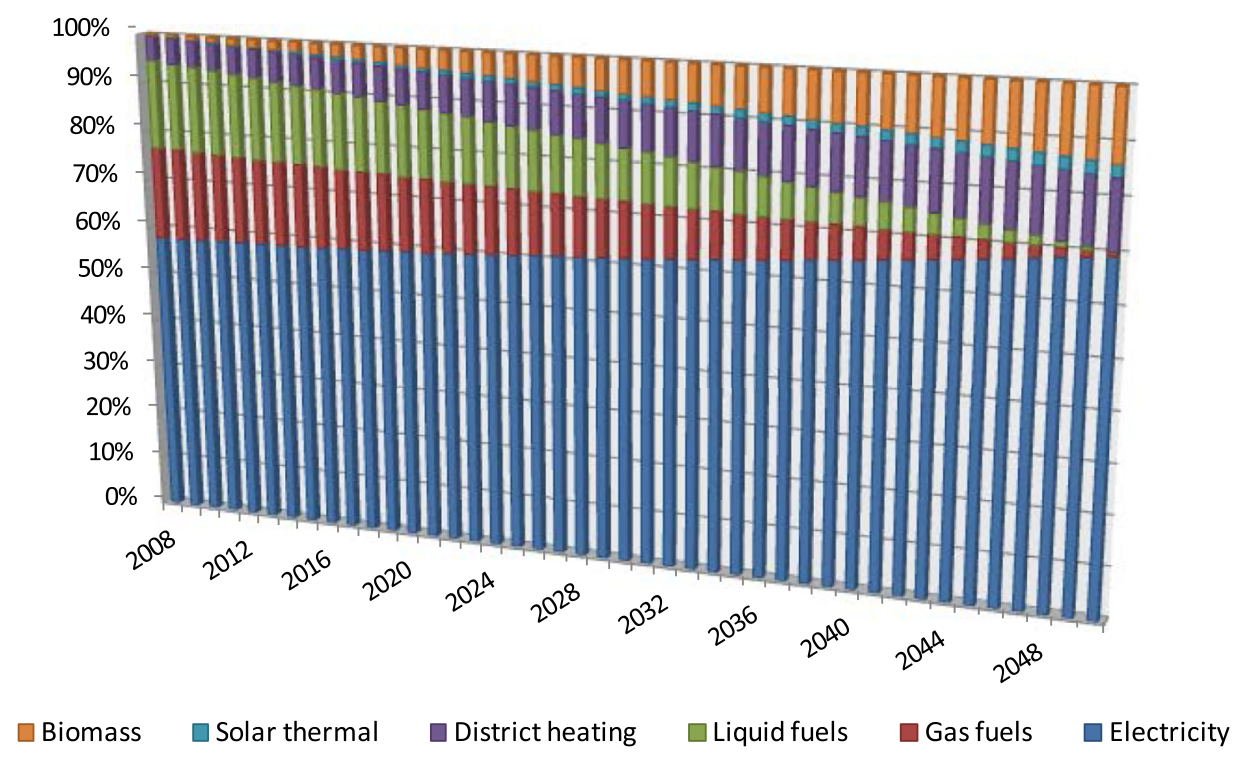

Fig. 10. Fuel mix for the Croatian services sector. 


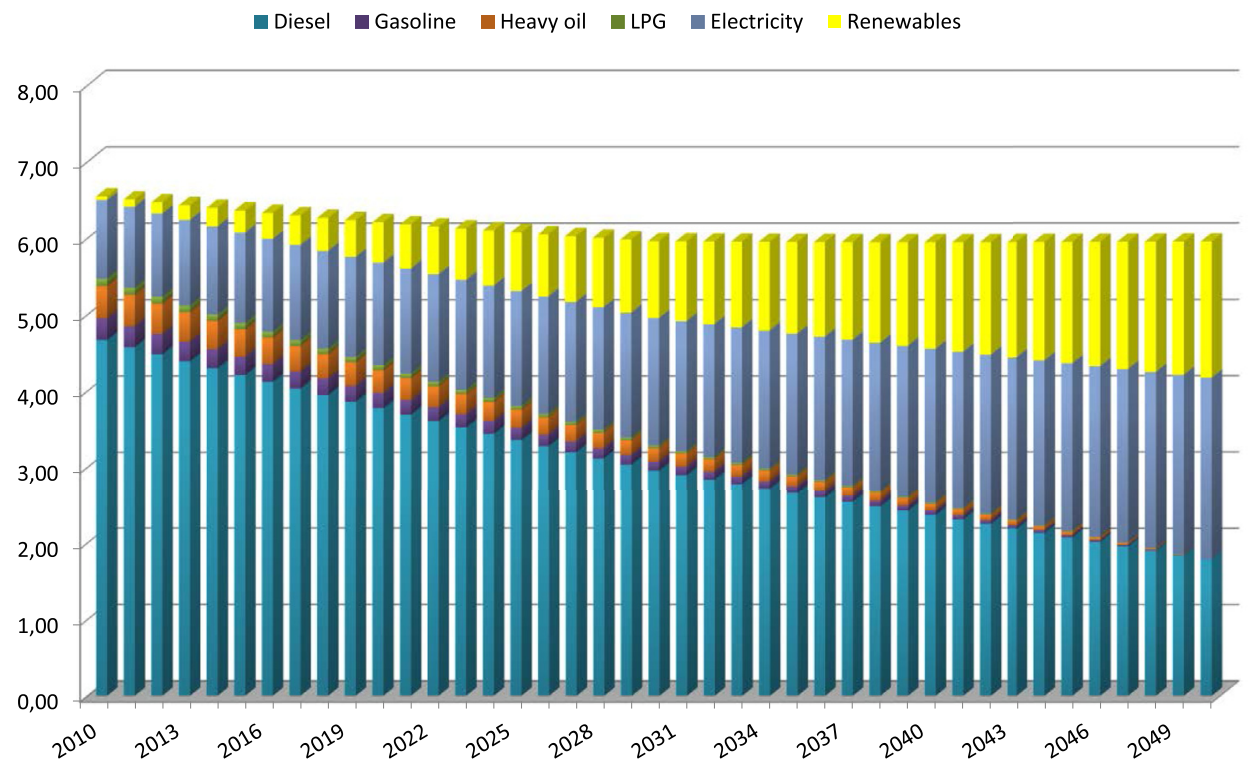

Fig. 11. Long term energy demand scenarios of Croatian construction sector.

heavily dependent on liquid fossil fuel. One of the possibilities was a graduate switch to biofuels which could be expected in the future as well as gradual introduction of synthetic fuels. Gradual switch towards biofuels was expected based on the renewable energy sources directive which prescribes required biofuel share in the transport sector. In all categories 5\% increase in energy efficiency was assumed until the year 2050 in $\left[\mathrm{GJ} / \mathrm{m}^{2}\right]$ or $[\mathrm{GJ} / \mathrm{con}$ struction site]. This figure was arbitrary, but it reflected current EU efforts towards energy efficiency improvements in all sectors. For all the specific energy demand categories 50\% increase until 2050 has been assumed [ $\mathrm{m}^{2} /$ capita] and [building permits/capita]. Although a significant increase for the specific energy demand categories has been assumed overall final energy demand has had a continuous decline until the year 2050. First reason for this was the expected increase in energy efficiency while the second reason was a steady decrease of population in Croatia until the year 2050.
Although agriculture, as well as construction sector, were not so relevant when comparing it to the total national final energy demand they were still interesting to analyse. Agriculture represents $7.2 \%$ of Croatian GDP. It is important for Croatian economy and society in general because $42.7 \%$ of Croatian population is classified as rural. Agriculture final energy demand model was scenario based. One of the main assumptions was the expected increase of tertiary sector which would directly cause the increase in agricultural sector. This was combined with excellent agriculture potentials that were being unused in the last 20 years. With Croatia entering the EU, market for Croatian agricultural products has become much bigger. One of the key elements in the future agriculture production will be the efficiency of the agriculture process itself. From one side increase in energy efficiency of the machinery is important, but from the other side land concentration will play a key role in increasing future agricultural production. Currently agricultural production in Croatia is characterized by many small

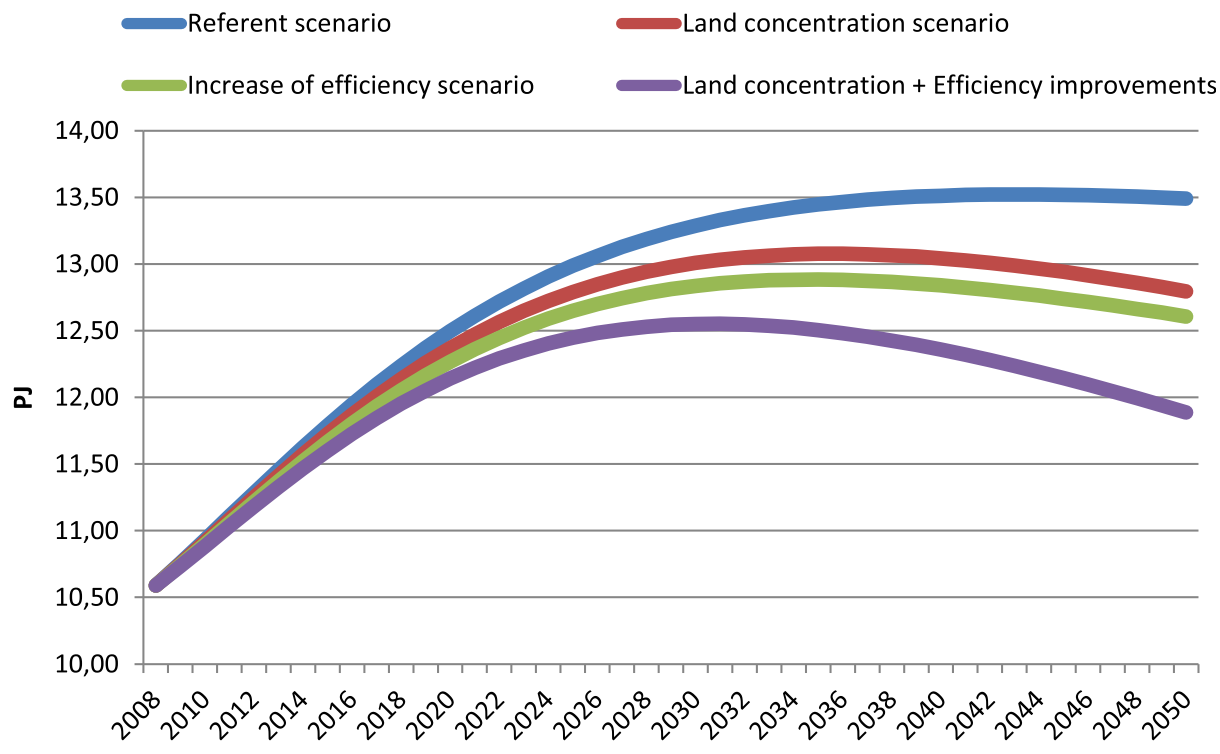

Fig. 12. Long term energy demand scenarios of Croatian agricultural sector. 


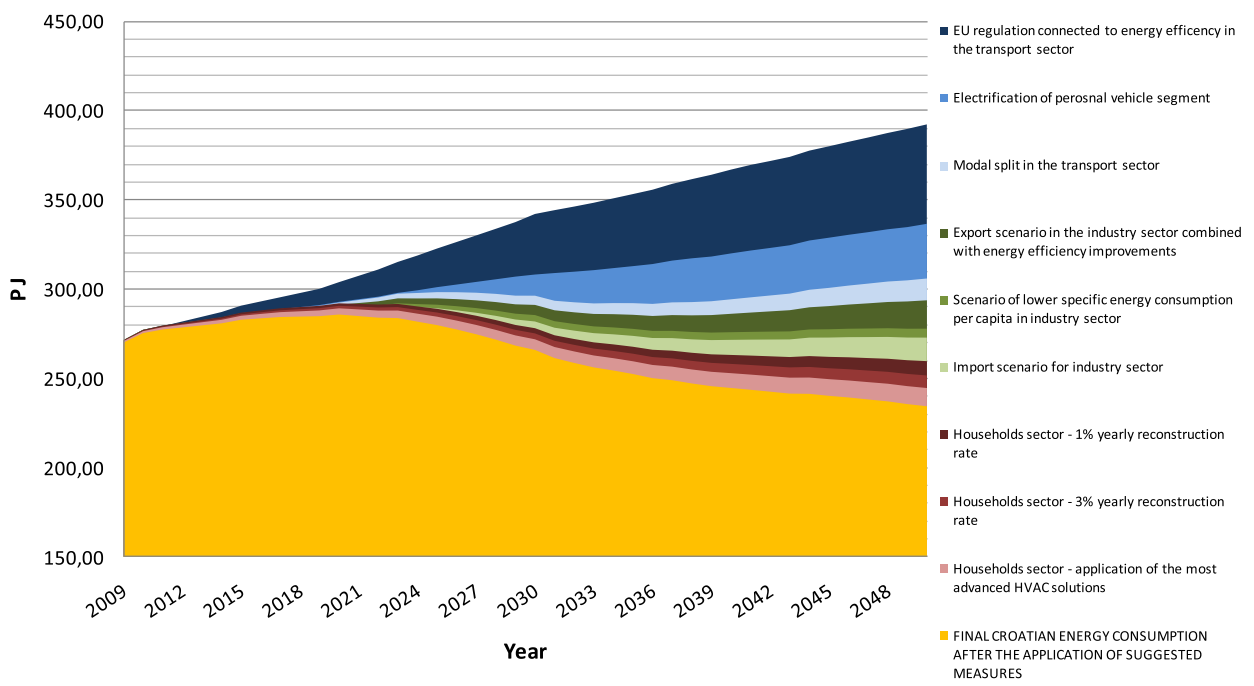

Fig. 13. Possible energy efficiency wedges calculated with NeD model.

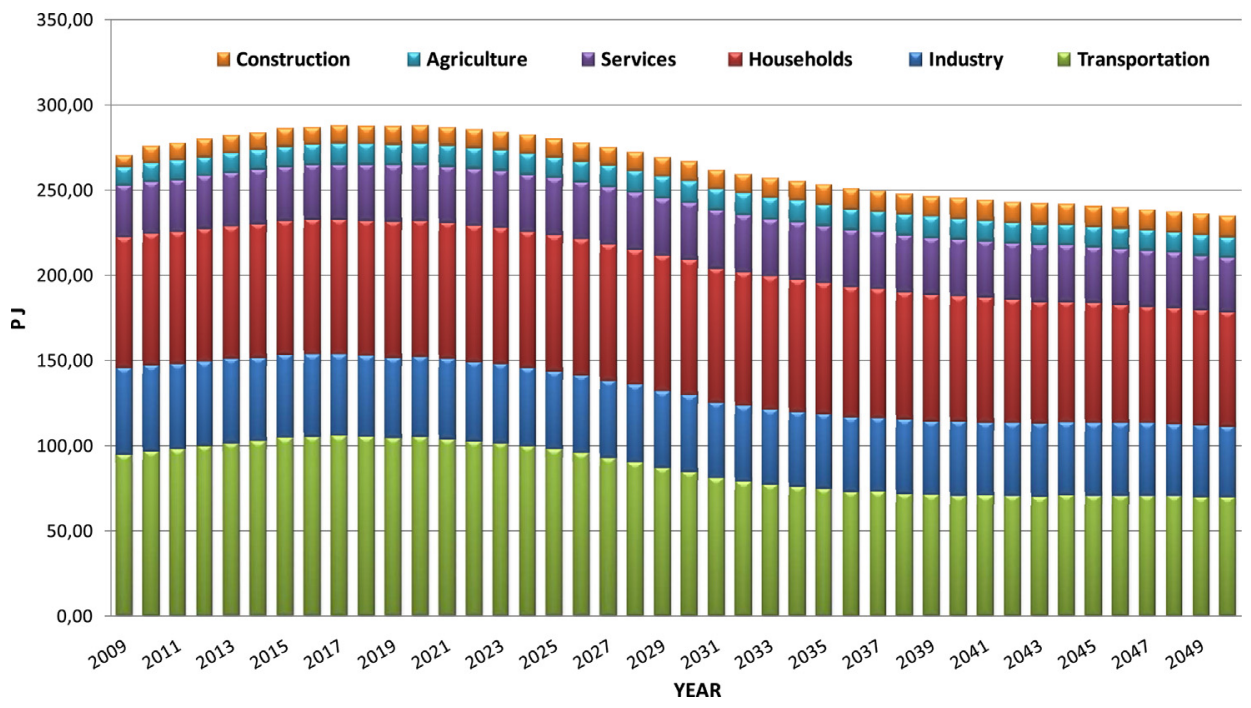

Fig. 14. Energy efficiency scenario calculated with NeD model by implementing energy efficiency wedges suggested in Fig. 13.

estates. Their cultivation presents a large dissipation of energy (Fig. 12). For that reason referent scenario has assumed an increase in agricultural production due to country's strategic direction. Two main mechanisms regarding energy efficiency have been applied in this version of NeD model. One being land concentration scenario and the other being energy efficiency improvements on agricultural machinery scenario. Due to land concentration final energy demand could be decreased by $5.2 \%$ in the year 2050 . Additional $7 \%$ decrease on final energy demand could be achieved by implementing energy efficiency improvements in the segment of agricultural machinery.

One of the key features of the NeD model was to show energy efficiency wedges for the whole country. Potential energy efficiency wedges for three main and most important economic sectors (transport, industry and households) are shown in Fig. 13. First three wedges in Fig. 13 refer to three major transport energy policies (the EU regulation on engine efficiency, electrification of personal vehicles fleet and modal split). Next three wedges refer to industry (export scenario with increased energy efficiency, lower specific consumption scenario and high import scenario). Final three wedges refer to households (1\% yearly reconstruction rate, $3 \%$ reconstruction rate, additional application of the most advanced $\mathrm{HVAC}^{4}$ solutions). The analysis has shown that the potential energy savings could go up to $157 \mathrm{PJ}$ in the year 2050 which would present a $40 \%$ decrease in energy consumption if compared to frozen energy efficiency scenario. Based on the set parameters, explained in Refs. [24] and [26], transport sector has the biggest potential in energy efficiency improvements. Households sector was not calculated with the highest and the most strict energy policy implementation.

The energy demand scenario coloured in yellow (FINAL CROATIAN ENERGY CONSUMPTION AFTER THE APPLICATION OF SUGGESTED MEASURES) in Fig. 13 (in web version) is presented in a more detailed way in Fig. 14. As expected main energy savings were achieved in the households and transport sector.

\footnotetext{
${ }^{4}$ Heating, ventilation and air conditioning.
} 


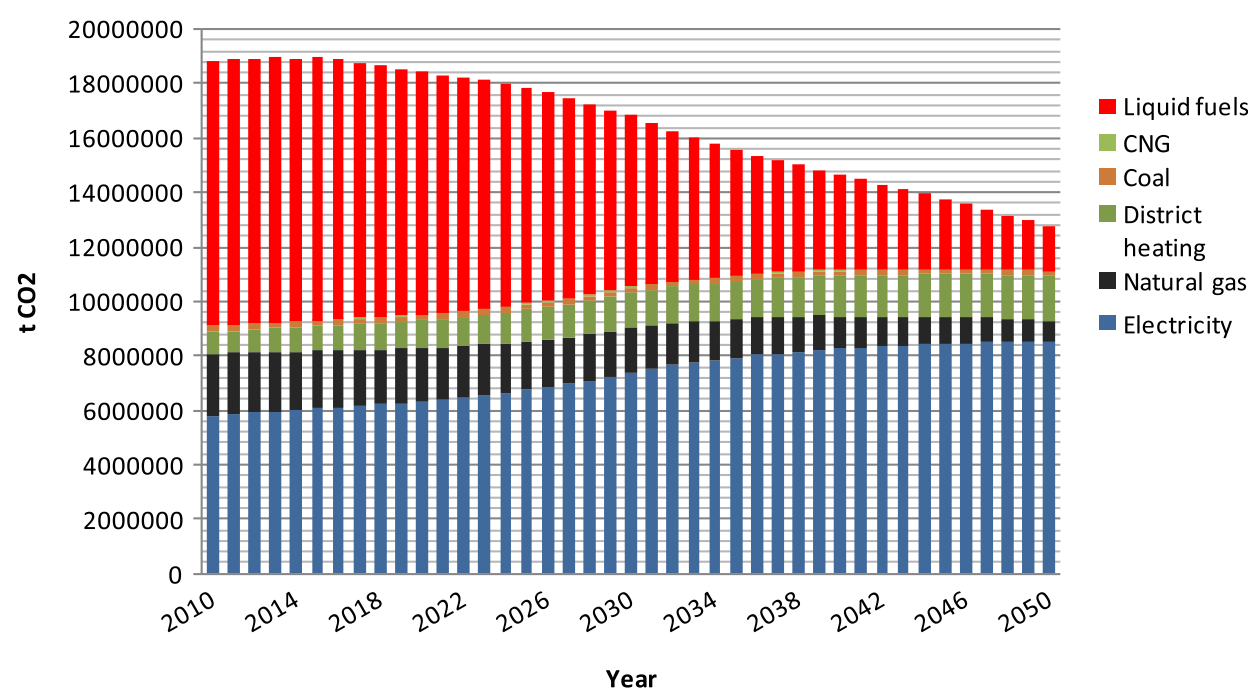

Fig. 15. $\mathrm{CO}_{2}$ emissions of the energy efficiency scenario calculated with the NeD model.

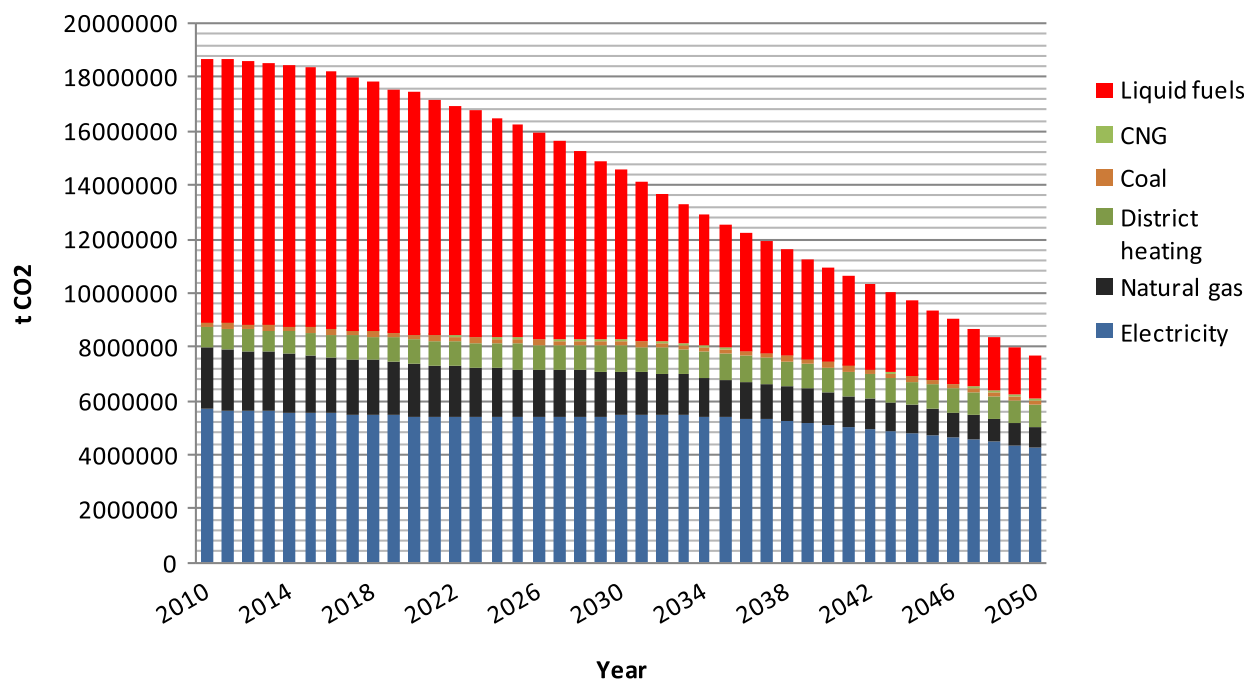

Fig. 16. $\mathrm{CO}_{2}$ emissions of the energy efficiency scenario calculated with the NeD model with electricity conversion factor corrected.

After all sectoral energy demands and fuel mixes were calculated they were imported into the GHG mode which was used for calculating $\mathrm{CO}_{2}$ emissions for every energy demand scenario.

Based on the high intake of renewables through most of the sectors which was followed by high electrification process, also through most of the sectors, $\mathrm{CO}_{2}$ emission could be reduced substantially until the year 2050. If comparing years 2010 and 2050 significant $\mathrm{CO}_{2}$ reductions could be achieved with careful and rational energy demand planning. NeD model calculated 38\% lower $\mathrm{CO}_{2}$ emission in the year 2050 if compared to 2010. Scenario in Fig. 15 was calculated by the same electricity to $\mathrm{CO}_{2}$ conversion factor which was not realistic. The same approach was used to calculate the GHG emissions from district heating. Until the year 2050 it is expected for the electricity generation and district heating sector to be more $\mathrm{CO}_{2}$ free than today.

The same scenario as in Fig. 15 is presented with one modification in Fig. 16. Electricity to $\mathrm{CO}_{2}$ conversion factor as well as district heating to $\mathrm{CO}_{2}$ conversion factor were assumed to be $50 \%$ lower in the year 2050 than it was in the year 2010. Base on the scenario presented in Fig. $16 \mathrm{CO}_{2}$ emissions could be lowered for $60 \%$ in the year 2050 if compared to the year 2010. Lowering the
$\mathrm{CO}_{2}$ conversion factor was in line with the constant EU efforts in decarbonising the energy supply (electricity). Some countries are even now talking on $100 \%$ renewable energy supply (electricity) until 2050.

\section{Conclusion}

NeD model presents a unified energy model that can be used for the analysis of a whole country's final energy demand. Its methodology is applicable to any other country under the condition that all local specifics would be described and quantified through the model. In the case of Croatia, results calculated by NeD model have shown significant energy demand reduction potentials as well as GHG emission potentials in the forthcoming long term period. Transport sector, as well as buildings, presented the biggest potential in energy demand management, which was fairly expected. If analysing energy efficiency scenario calculated with NeD model, after all the suggested energy efficiency wedges were implemented, energy demand in the year 2050 could be lower more than $16 \%$ if compared to the year 2010. Maximum GHG emission savings 
calculated with NeD model were $60 \%$ in the year 2050 if compared to the reference year.

\section{Acknowledgement}

The financial support is gratefully acknowledged from the Croatian Science Foundation (09/128) through "ICT-aided integration of Electric Vehicles into the Energy Systems with a high share of Renewable Energy Sources" project.

\section{Nomenclature}

$A_{\mathrm{i} \text { spec }}^{\mathrm{z}} \quad$-specific available surface of a certain category of a subsector in a specific year (eg. hospitals, schools etc.) [ $\mathrm{m}^{2} /$ capita]

$B_{\mathrm{i}}^{\mathrm{z}} \quad$-available floor area of a certain category of a subsector in a specific year (eg. hospitals, schools etc.) $\left[\mathrm{m}^{2}\right]$

$P^{z} \quad$-population in a specific year

$z \quad$-year for which the calculation is done

$\mathrm{EI}_{\mathrm{a}} \quad$-energy intensity of the agricultural production of a specific crop $(\mathrm{MJ} / t)$

$E_{\mathrm{a}} \quad$-energy intensity of the agricultural production of a specific crop (MJ/ha)

$P_{\mathrm{a}} \quad$-crop productivity (t/ha)

$\mathrm{EC}_{\mathrm{a}} \quad$-energy consumption of the agricultural production of specific crop (MJ/year)

$\mathrm{CP}_{\mathrm{a}} \quad$-crop production (t/year)

$\mathrm{EC}_{\mathrm{ah}}$-energy consumption of animal husbandry for a specific kind of animal (MJ/year)

$\mathrm{EI}_{\mathrm{ah}} \quad$-energy intensity of animal husbandry for a specific kind of animal (MJ/animal)

NOE -number of animals (animal/year)

$F_{\mathrm{ij}}^{\mathrm{z}} \quad$-yearly energy demand of a different fuel type for a certain energy consumption category [PJ]

$L_{\mathrm{ij}}^{\mathrm{Z}}$ spec $\quad$-specific energy consumption of a different fuel type for a certain energy consumption category $\left[\mathrm{PJ} / \mathrm{m}^{2}\right][\mathrm{PJ} /$ construction site]

$C_{\mathrm{j}}^{\mathrm{z}} \quad$-yearly property of a certain energy consumption category $\left[\mathrm{m}^{2}\right]$ [number of construction sites]

$G_{\mathrm{i}}^{\mathrm{z}} \quad$-yearly amount of $\mathrm{CO}_{2}$ emitted from specific fuel type $\left[\mathrm{tCO}_{2}\right]$

$S_{\mathrm{i}}^{\mathrm{z}} \quad$-specific $\mathrm{CO}_{2}$ emission conversion factor of a certain fuel $\left[\mathrm{tCO}_{2} / \mathrm{GJ}\right]$

$K_{\mathrm{i}}^{\mathrm{Z}} \quad$-yearly amount of various fuel consumed [GJ]

\section{References}

[1] Croatian historical energy balances. Energy Institute Hrvoje Požar. www.eihp. hr [accessed 02.05.2013].

[2] Hong L, Lund H, Mathiesen BV, Moller B. 2050 pathway to an active renewable energy scenario for Jiangsu province. Energy Policy 2013;53:267-78.
[3] Krajačić G, Duić N, Zmijarević Z, Mathiesen BV, Vučinić AA, Carvalho MG. Planning for a 100\% independent energy system based on smart energy storage for integration of renewables and $\mathrm{CO}_{2}$ emissions reduction. Appl Therm Eng 2011;31:2073-83.

[4] Yu S, Zhu K. A hybrid procedure for energy demand forecasting in China,. Energy 2012;37:396-404.

[5] Kialashaki A, Reisel JR. Modeling of the energy demand of the residential sector in the United States using regression models and artificial neural networks. Appl Energy 2013;108:271-80.

[6] Bhattacharyya SC, Timilsina GR. Modelling energy demand of developing countries: are the specific features adequately captured. Energy Policy 2010;38:1979-90.

[7] Dedinec A, Markovska N, Taseska V, Duić N, Kanevce G. Assessment of climate change mitigation potential of the macedonian transport sector. Energy 2013;57:177-87.

[8] Ćosić B, Markovska N, Krajačić G, Taseska V, Duić N. Environmental and economic aspects of higher RES penetration into Macedonian power system. Appl Therm Eng 2012;43:158-62.

[9] Suganthi L, Samuel AA. Energy models for demand forecasting - a review. Renew Sustain Energy Rev 2012;16:1223-40.

[10] Koopmans CC, Velde DW. Bridging the energy efficiency gap: using bottom up information in a top down energy demand model. Energy Econ 2001;23: $57-75$.

[11] Fleiter T, Worrell E, Eichhmmer W. Barriers to energy efficiency in industrial bottom up energy demand models - a review. Renew Sustain Energy Rev 2011;15:3099-111.

[12] Gouveia JP, Fortes P, Seixas J. Projections of energy services demand for residential buildings: insights from a bottom up methodology. Energy 2012;47: 430-42.

[13] Rout UK, Vol A, Singh A, Fahl U, Blesl M, Gallachoir BPO. Energy and emissions forecast of China over a long-time horizon. Energy 2011;36:1-11.

[14] Bhattacharyya SC, Timilsina GR. Energy demand models for policy formulation, policy research working paper. World Bank; 2009.

[15] EUROSTAT. http://epp.eurostat.ec.europa.eu/portal/page/portal/eurostat/ home/[accessed 02.05.2013].

[16] Segurado R, Krajačić G, Duić N, Alves L. Increasing the penetration of renewable energy resources in S. Vicente, Cape Verde. Appl Energy 2011;88: 466-72.

[17] Ćosić B, Krajačić G, Duić N. A 100\% renewable energy system in the year 2050: the case of Macedonia,. Energy 2012;48:80-7.

[18] Hong L, Lund H, Moller B. The importance of flexible power plant operation for Jiangsu's wind integration,. Energy 2012;42:499-507.

[19] Busuttil A, Krajačić G, Duić N. Energy scenarios for Malta. Int J Hydrogen Energy 2008;33:4235-46.

[20] Huang Y, Bor YJ, Peng CY. Long-term forecast of Taiwan's energy supply and demand: LEAP model application. Energy Policy 2011;39:6790-803.

[21] Amirnekooei K, Ardehali MM, sadri A. Integrated resources planning for Iran: development of reference energy system, forecast, and long-term energyenvironment plan. Energy 2012;46:374-85.

[22] Jovanovic M, Afgan N, Bakic V. An analytical method for the measurement of energy system sustainability in urban areas. Energy 2010;35:3909-20.

[23] Hainoun A, Seif-Eldin MK, Almoustafa S. Analysis of the Syrian long-term energy and electricity demand projection using end-use methodology. Energy policy 2006;34:1958-70.

[24] Pukšec T, Mathiesen BV, Duić N. Potentials for energy savings and long term energy demand of croatian households sector. Appl Energy 2013;101: $15-25$.

[25] Bačelić Z, Pukšec T, Mathiesen BV, Duić N. Modelling energy demand of croatian industry sector. Int J Environ and Sustain Develop 2014;13(1): 74-92.

[26] Pukšec T, Krajačić G, Lulić Z, Mathiesen BV, Duić N. Forecasting long-term energy demand of croatian transport sector. Energy 2013:57:169-76.

[27] Irsag B, Pukšec T, Duić N. Long term energy demand projection and potential for energy savings of croatian tourism-catering trade sector. Energy 2012;48: $398-405$. 